\title{
Development of multiplex loop-mediated isothermal amplification for three foodborne pathogens
}

\author{
Cong XU' ${ }^{1}$, Hongbin $\mathrm{LUO}^{2 *}$ (D), Yun $\mathrm{ZHANG}^{3}$
}

\begin{abstract}
Staphylococcus aureus, Salmonella, and Shigella are three major foodborne pathogenic microorganisms that cause global public health problems. We developed a multiplex loop-mediated isothermal amplification (mLAMP) assay for simultaneous detection of S. aureus nuc, Salmonella fim $Y$, and Shigella ipaH in fresh fruit juice using three sets of primers. In addition, three different restriction enzyme cleavage sites were designed in each forward inner primer (FIP), namely, XhoI in nuc FIP, KpnI in fim Y FIP, and BamHI in ipaH FIP. DNA was amplified using the LAMP assay at $64{ }^{\circ} \mathrm{C}$ for $50 \mathrm{~min}$ followed by endonuclease restriction digestion to separate the LAMP products of three pathogens. The minimum amount of genomic DNA of S. aureus, Salmonella, and Shigella that could be detected by mLAMP was $100 \mathrm{fg} / 25 \mu \mathrm{L}$, whereas for mPCR, it was $1 \mathrm{pg} / 25 \mu \mathrm{L}$. The artificially contaminated juice can also be detected by mLAMP after enrichment, which had the limit of detection (LOD) of $2 \mathrm{CFU} / 10 \mathrm{~mL}$. In conclusion, the mLAMP developed in this study could be potentially used in the detection of S. aureus, Salmonella, and Shigella in food, particularly as a primary screening method in developing areas.
\end{abstract}

Keywords: multiplex LAMP; Staphylococcus aureus; Salmonella; Shigella.

Practical Application: Detection of foodborne pathogens.

\section{Introduction}

According to the World Health Organization (2015), unsafe food causes over 200 human diseases due to harmful bacteria, viruses, parasites or chemical substances, ranging from diarrhoea to cancers, and foodborne and waterborne diseases kill about two million people each year. Foodborne pathogens can cause a wide range of diseases including severe diarrhea and severe infections. Staphylococcus aureus, Salmonella enterica, and Shigella are three major foodborne pathogenic microorganisms that cause public health problems around the world. It is estimated that non-typhoidal S. enterica causes 93.8 million cases of acute gastroenteritis and 155,000 deaths every year around the world, of which $85 \%$ are foodborne (Food and Agriculture Organization of the United Nations, 2016). Shigellosis has high morbidity and mortality, particularly in resource-poor countries, where 167 million cases of diarrhea and over a million deaths occur annually (Von Seidlein et al., 2006). These three pathogens are responsible for $26.71 \%$ of bacteria foodborne events in China (Liu et al., 2016).

Based on the public health issue and economic losses caused by S. aureus, Salmonella and Shigella, these three pathogens should be monitored in foods (World Health Organization, 2003, 2015). The gold standard for S. aureus, Salmonella and Shigella testing is culture-based assays, which typically involve culture, identification, biochemical and serological detection. However, these assays are relatively complicated and time-consuming. Therefore, more rapid and simple methods are warranted, mainly includes immunology and molecular biology (Amani et al., 2015; Chen et al., 2015; Maerle et al., 2014; Nouri et al., 2018; Shao et al., 2011).

Loop-mediated isothermal amplification (LAMP) is a simple, rapid, sensitive, and specific method for the detection of pathogens that was developed by Notomi et al. (2000). Since it was developed, LAMP was used for detection and identification of viruses, bacteria and parasites (Huy et al., 2012; Imai et al., 2006; Shao et al., 2011; Sun et al., 2017). Compared to other detection methods, one of the most significant advantages of LAMP is its low cost, as this implies that it has a huge potential application value for pathogen detection. The purpose of this study was to develop an efficient and inexpensive assay for the detection of S. aureus, Salmonella, and Shigella, and assessed the application potential of mLAMP in food. This is the first time that mLAMP has been utilized in the simultaneous detection of S. aureus, Salmonella, and Shigella in juice using a single reaction.

\section{Materials and methods}

\subsection{Bacterial strains and culture conditions}

Seventeen standard strains were used for specificity and sensitivity testing in this study (Table 1). The culture medium of S. aureus, Salmonella, Shigella, and Escherichia coli was nutrient agar (NA), whereas Listeria monocytogenes was cultured in brain heart infusion (BHI). All strains were cultured at $37^{\circ} \mathrm{C}$. 


\subsection{DNA extraction}

Genomic DNA was extracted from each bacterial strain after overnight growth using a QIAGEN DNA extraction kit (DNeasy kit, QIAGEN, German). The concentration of the extracted DNA was determined at A260/280 by spectrophotometer (Shimadzu, UV-1700) and stored under at $-20{ }^{\circ} \mathrm{C}$.

\subsection{Primer design}

The sequences of the $S$. aureus nuc gene, $S$. enterica fim $Y$ gene, and Shigella ipaH gene were downloaded from NCBI and used in designing primers using Primer Explorer 5. Primer

Table 1. The 17 bacterial strains used in this study.

\begin{tabular}{clcl}
\hline No. & \multicolumn{1}{c}{ Bacterial species } & $\begin{array}{c}\text { Strain serial } \\
\text { number }\end{array}$ & Origin \\
\hline 1 & Staphylococcus aureus & 10384 & China Center of \\
2 & S. aureus & 21600 & Industrial Culture \\
3 & S. aureus & 21601 & Collection, CICC \\
4 & S. aureus & 23656 & \\
5 & Salmonella & 21482 & \\
6 & Salmonella & 21484 & \\
7 & Salmonella & 21493 & \\
8 & Salmonella & 21513 & \\
9 & Shigella & 21534 & \\
10 & Shigella & 21535 & \\
11 & Shigella & 21680 & \\
12 & Escherichia coli & 10389 & \\
13 & E. coli & 10667 & \\
14 & E. coli & 21530 & 21633 \\
15 & L. monocytogenes & 21635 & 23929 \\
16 & L. monocytogenes & L. monocytogenes &
\end{tabular}

sequences were verified with BLAST ${ }^{\circledast}$ after design. Three sets of primers were used in the LAMP assays, and each set was used to amplify 17 DNA sequences of S. aureus, Salmonella, and Shigella (Table 1). XhoI was introduced into nuc FIP (Forward Inner Primer), KpnI was introduced into fim Y FIP and BamHI was introduced into ipaH FIP (Table 2). Three sets of primers were used in this study (Table 2).

\subsection{LAMP assay}

Each LAMP reaction contained the following: $12.5 \mu \mathrm{L}$ of a 2× Master Mix (WarmStart LAMP Kit, NEB, USA), 5 pmol each of F3 and B3, 40 pmol each of FIP and BIP (backward inner primer), $1 \mu \mathrm{L}$ of DNA, and $\mathrm{H}_{2} \mathrm{O}$ to a final reaction volume of $25 \mu \mathrm{L}$. LAMP reactions were performed under the isothermal condition of $64{ }^{\circ} \mathrm{C}$ for $50 \mathrm{~min}$ and then $80{ }^{\circ} \mathrm{C}$ for $5 \mathrm{~min}$ to terminate the reaction.

For multiplex LAMP (mLAMP), the following reaction componets were employed: $12.5 \mu \mathrm{L}$ of a $2 \times$ Master Mix, $1.67 \mathrm{pmol}$ each of $n u c, f i m Y$, and $i p a H$ F3 and B3, 13.3 pmol each of $n u c$, fim $Y$, and ipaH FIP and BIP, $1 \mu \mathrm{L}$ each of DNA, and $\mathrm{H}_{2} \mathrm{O}$ to a final reaction volume of $25 \mu \mathrm{L}$. Each assay was repeated three times.

\section{5 mPCR assay}

Multiplex PCR (mPCR) was conducted in parallel with the mLAMP assay. Each mPCR consisted of the following: $12.5 \mu \mathrm{L}$ of a Taq premix (Premix Taq, TakaRa, China), 1.67 pmol of each nuc, fim $Y$, and ipaH PCR primers, $1 \mu \mathrm{L}$ each of $S$. aureus, Salmonella, Shigella DNA template, and $\mathrm{H}_{2} \mathrm{O}$ to a final reaction volume of $25 \mu \mathrm{L}$. mPCR was performed using the following conditions: $94^{\circ} \mathrm{C}$ for $3 \mathrm{~min}$; followed by 30 cycles of $94^{\circ} \mathrm{C}$ for $30 \mathrm{~s}, 52^{\circ} \mathrm{C}$ for $30 \mathrm{~s}$, and $72{ }^{\circ} \mathrm{C}$ for $20 \mathrm{~s}$; and a final extension at $72{ }^{\circ} \mathrm{C}$ for $5 \mathrm{~min}$. Each assay was repeated three times.

Table 2. Primers used in this study.

\begin{tabular}{|c|c|}
\hline Primer name & Sequence $\left(5^{\prime} \rightarrow 3^{\prime}\right)$ \\
\hline \multicolumn{2}{|l|}{ LAMP primers } \\
\hline nuc F3 & AAAAGATGGTAGAAAATGCHAAG \\
\hline nuc B3 & TGTTCATGTGTATTGTTAGGTT \\
\hline$n u c$ FIP & ACGCTAAGCCACGTCCATATTCTCGAG(XhoI)AAAATTGAAGTCGAGTTTGACA \\
\hline nuc BIP & TATGCTGATGGAAAAATGGTAAACGTAAACATAAGCAACTTTAGCCAAG \\
\hline fim Y F3 & AGAAAGCTTTGCCTGTGG \\
\hline fim Y B3 & WAACCTCGCTTATCGGAA \\
\hline fim Y FIP & AGCAAAGCGTACCTTATCATCGGGTACC $(K p n I)$ GTTAAGGAGGGTGATAAGTTG \\
\hline fim Y BIP & GACGTGCTATTTCTTTTAAAGAGGCAGCTTTAGCCGTACTGAC \\
\hline ipaH F3 & GCTGGAAAAACTCAGTGCCT \\
\hline ipaH B3 & GGAACATTTCCCTGCCCA \\
\hline ipaH FIP & CGACACGGTCCTCACAGCTCGGATCC(BamHI)TTCGACAGCAGTCTTTCGC \\
\hline ipaH BIP & ATCTCCGGAAAACCCTCCTGGTAGCGCCGGTATCATTATCGA \\
\hline \multicolumn{2}{|l|}{ PCR primers } \\
\hline nuc F3 & AAAAGATGGTAGAAAATGCHAAG \\
\hline nuc B3 & TGTTCATGTGTATTGTTAGGTT \\
\hline fim Y F1 & AAGGAGGGTGATAAGTTGTTT \\
\hline $\operatorname{fim} Y \mathrm{~B} 1$ & AGCCGTACTGACTGGTTGA \\
\hline ipaH F1 & CGCGCTCACATGGAACAA \\
\hline ipaH B1 & AGTTTCTCTGCGAGCATGG \\
\hline
\end{tabular}




\subsection{Restriction endonuclease analysis}

The LAMP products were digested by restriction endonucleases XhoI, KpnI, and/or BamHI at $37^{\circ} \mathrm{C}$ for $1 \mathrm{~h}$. Each $30-\mu \mathrm{L}$ restriction endonuclease system consisted of $3 \mu \mathrm{L}$ of the restriction enzyme buffer, $1 \mu \mathrm{L}$ of each enzyme, $3 \mu \mathrm{L}$ of the LAMP product, and $\mathrm{H}_{2} \mathrm{O}$.

\subsection{Specificity and sensitivity testing}

The specificity of the LAMP assays used in this study was tested on 17 strains (Table 1), which included five foodborne pathogens. The specificity of the restriction endonuclease reactions was assessed by cross enzyme digestion. The LAMP products of S. aureus, Salmonella, and Shigella were digested by XhoI, KpnI, and BamHI separately.

To evaluate the sensitivity of the mLAMP assays, serial 10 -fold dilutions of the DNA templates were used.

\section{8 $\mathrm{mLAMP}$ for the simultaneous detection of S. aureus, Salmonella, and Shigella in artificially contaminated fresh fruit juice}

The present study assessed the application potential of mLAMP in food. Artificially contaminated fresh fruit juices were prepared as described by Shao et al. and Garrido with modifications (Garrido-Maestu et al., 2017; Shao et al., 2011). The juices used in this study were purchased from a local supermarket. S. aureus, S. enterica, and Shigella were incubated in nutrient broth (NB) at $37^{\circ} \mathrm{C}$ for shaking overnight. The concentration of three pathogens were determinated by CFU (colony forming unit) counting, meanwhile $\mathrm{OD}_{600}$ was measured. Bacterium was diluted in NB, final inoculum concentration was adjusted to $100 \mathrm{CFU} / \mathrm{mL}$, $50 \mathrm{CFU} / \mathrm{mL}, 10 \mathrm{CFU} / \mathrm{mL}, 5 \mathrm{CFU} / \mathrm{mL}, 2 \mathrm{CFU} / \mathrm{mL}, 1 \mathrm{CFU} / \mathrm{mL}$. $3 \mathrm{~mL}$ of bacteria (1 $\mathrm{mL}$ of each) were added to $10 \mathrm{~mL}$ of juice, and mixed with $87 \mathrm{~mL}$ of NB. This matrix was incubated for $18 \mathrm{~h}$ at $37^{\circ} \mathrm{C}$. After incubation, $1 \mathrm{~mL}$ of matrix was taken and DNA was extracted following the DNA extraction above. Each inoculum concentration was repeated three times.

\subsection{Product testing}

The LAMP, PCR, and digestion products were analyzed by electrophoresis on a $2 \%$ agarose gel containing $0.5 \mu \mathrm{g} / \mathrm{mL}$ Andy Safe (Applied Bioprobes, USA).

\section{Results}

\subsection{The specificity of LAMP assays and restriction endonuclease digestions}

Multiplex LAMP was used to simultaneously detect $S$. aureus, Salmonella, and Shigella. Three sets of primers corresponding to the nuc of S. aureus, the fim Y of Salmonella, and the ipaH of Shigella were designed (Table 2). Figure 1 shows that all three sets of primers were specific to their target templates, and no amplified DNA bands were detected after gel electrophoresis with non-target DNA (Figure 1).

In this study, S. aureus, Salmonella, and Shigella were detected by single-tube mLAMP assay, and restriction endonuclease digestion was used to analyze the mLAMP products due to

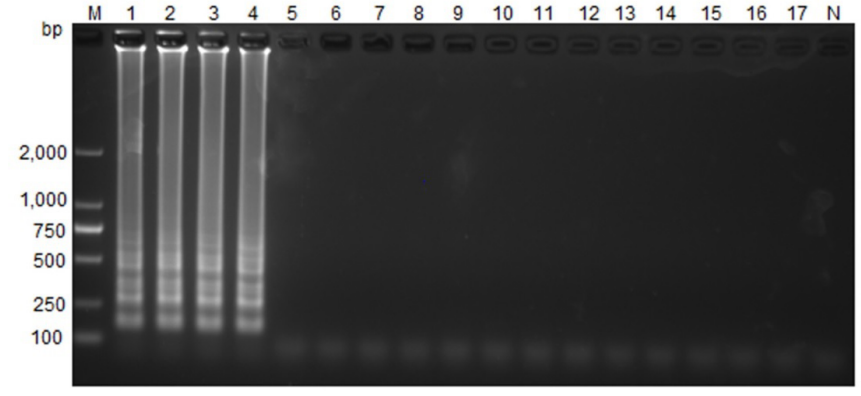

a

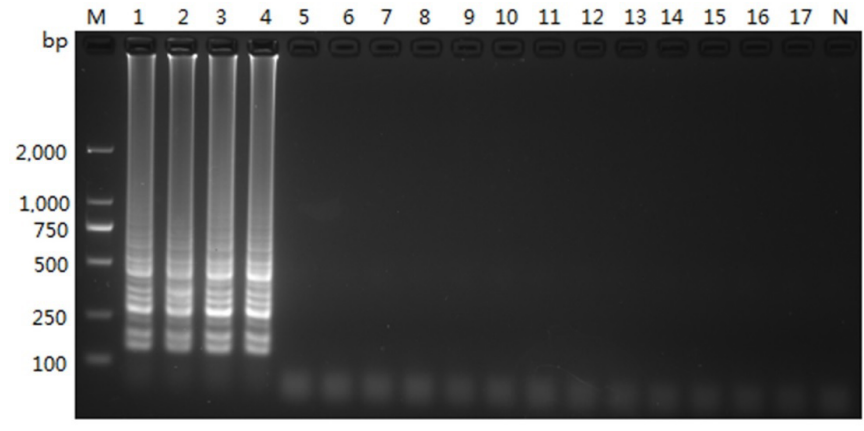

b

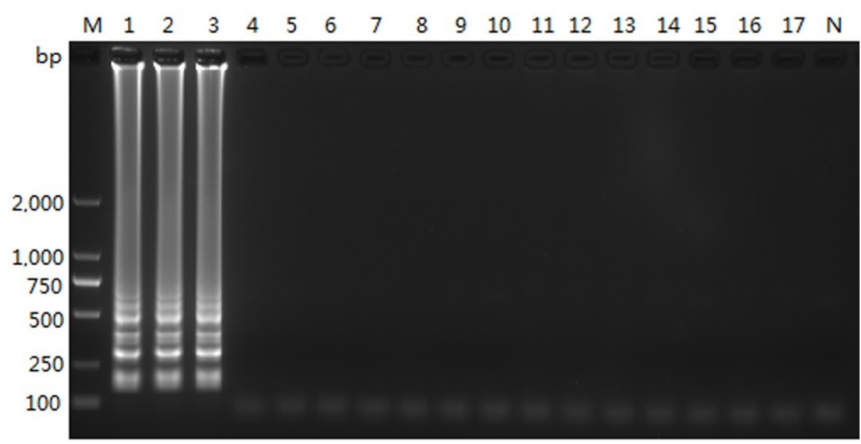

C

Figure 1. Specificity of LAMP assays. Lanes: M, 2,000-bp DNA marker; 12 14, 3 Escherichia coli strains; 15 17, 3 Listeria monocytogenes strains; N, negative control; (a) 1 4, 4 Staphylococcus aureus strains; 5 8, 4 Salmonella strains; 9 11 3 Shigella strains; (b) Lanes: 1 4, 4 Salmonella strains; 5 8, 4 Staphylococcus aureus strains; 9 11 3 Shigella strains; (c) Lane: 1 3, 3 Shigella strains; 4 7, 4 Staphylococcus aureus strains; $8 \sim 11,4$ Salmonella strains. Source: by Cong XU.

the different enzyme cut sites which introduced in three FIPs. Specific enzyme digestions were important in discriminating different templates. Figure 2 shows that the LAMP products of S. aureus, S. enterica, and Shigella were only digested by XhoI, $\mathrm{KpnI}$, and BamHI, respectively, as expected (Figure 2).

\section{2 mLAMP assay and multiplex restrict endonuclease digestion}

Three sets of primers and S. aureus, Salmonella, and Shigella DNA templates were added into one tube, where DNA was amplified; then the mLAMP products were analyzed by 
enzyme digestion. The DNA bands showed that the majority of the MLAMP products were digested by the three enzymes, whereas only a part of products were digested by XhoI, KpnI, or BamHI (Figure 3), meaning that there were three kinds of products in the MLAMP products and indicating that $S$. aureus, S. enterica, and Shigella DNA were all amplified in a single-vessel mLAMP system.

\subsection{The sensitivity of MLAMP and MPCR assays}

In this study, the sensitivity of the MLAMP assay was compared to the mPCR assay. Three pairs of primers were used in $\mathrm{mPCR}$. Three pairs of primers were used in $\mathrm{mPCR}$, namely, nuc F3/B3, fim Y F1/B1, and ipaH F1/B1 were listed in Table 2. Figure 3 shows that a 10 -fold dilution of DNA templates ranging from $1 \mathrm{ng}$ to $1 \mathrm{fg}$ per $25 \mu \mathrm{L}$ was used to test the sensitivity of the mLAMP and mPCR assays. The DNA ladder patterns using $1 \mathrm{ng}$ to $100 \mathrm{fg}$ of DNA were clearly visible, indicating that the limit of detection (LOD) of mLAMP was $100 \mathrm{fg} / 25 \mu \mathrm{L}$, whereas that of mPCR was $1 \mathrm{pg} / 25 \mu \mathrm{L}$ for target fragments of $181 \mathrm{bp}$, $126 \mathrm{bp}$, and $216 \mathrm{bp}$, as shown in the $1 \mathrm{ng}$ to $1 \mathrm{pg}$ lanes (Figure 4). Therefore, the mLAMP assay was 10 times more sensitive than the mPCR assay.

\subsection{MLAMP assay for artificially contaminated juice}

To assess the applicability of mLAMP in practical testing, S. aureus, Salmonella, and Shigella were simultaneously inoculated into juice. S. aureus, Salmonella, and Shigella were detected by mLAMP when the initial concentration was $>2 \mathrm{CFU} / 10 \mathrm{~mL}$

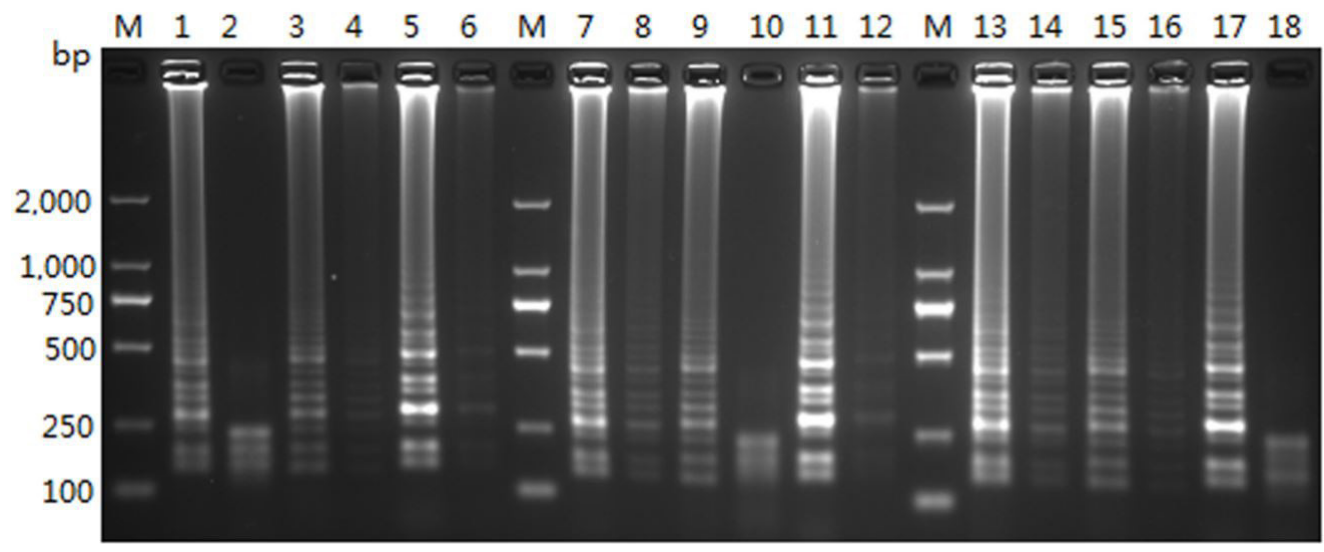

Figure 2. Specificity of restriction endonuclease reactions. Lanes: M, 2,000-bpDNA marker; 1,7,13, LAMP products of Staphylococcus aureus; 3, 9, and 15, LAMP products of Salmonella; 5, 11, and 17, LAMP product of Shigella; 2, 4, and 6, LAMP products of S. aureus, Salmonella, and Shigella digested by XhoI; 8, 10, and 12, LAMP products of S. aureus, Salmonella, and Shigella digested by KpnI; 6, 12, and 18, LAMP products of S. aureus, Salmonella, and Shigella digested by BamHI. Source: by Cong XU.

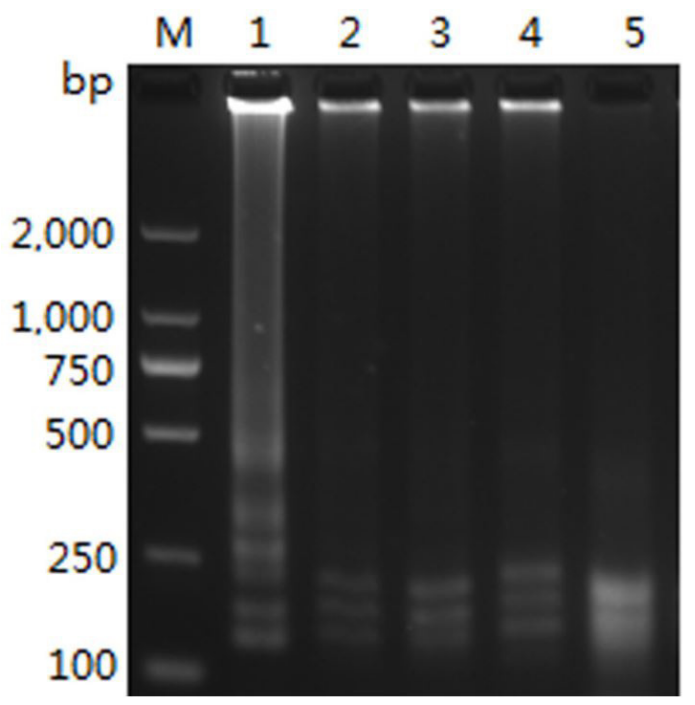

Figure 3. mLAMP assay and restriction endonuclease digestion. Lanes: M, 2,000-bp DNA marker; 1, mLAMP products of Staphylococcus aureus, Salmonella, and Shigella; 2 4, mLAMP products of $S$. aureus, Salmonella, and Shigella were separately digested by XhoI, KpnI, and BamHI separately; 5, mLAMP products of S. aureus, Salmonella, and Shigella were digested by XhoI, KpnI, and BamHI. Source: by Cong XU.

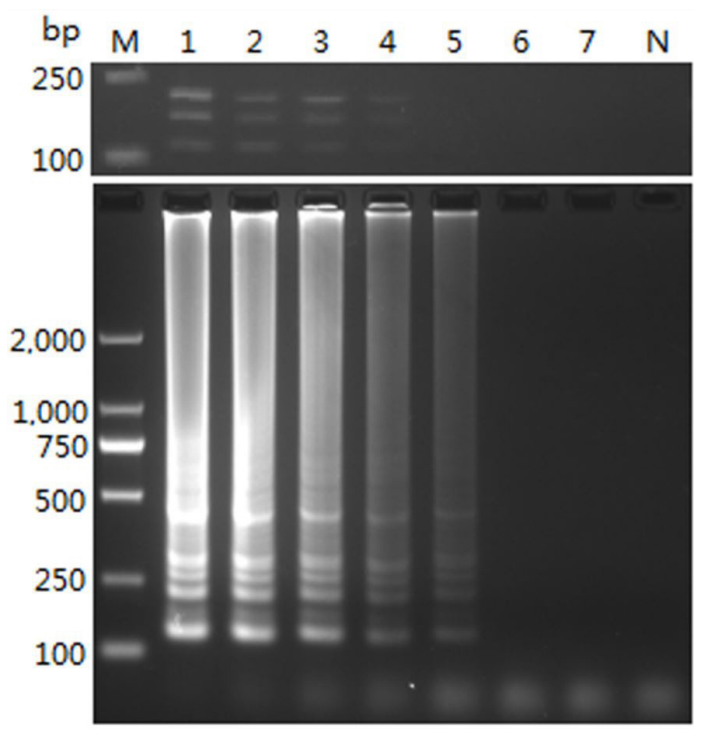

Figure 4. Sensitivity of mLAMP and mPCR assays. Upper panel: mPCR assay; lower panel: mLAMP assay. Lanes: M, 2,000-bp DNA marker; 1 7, Staphylococcus aureus, Salmonella, and Shigella DNA content was $1 \mathrm{ng}, 100 \mathrm{pg}, 10 \mathrm{pg}, 1 \mathrm{pg}, 100 \mathrm{fg}, 10 \mathrm{fg}$, and $1 \mathrm{fg}$; N, negative control. Source: by Cong XU. 


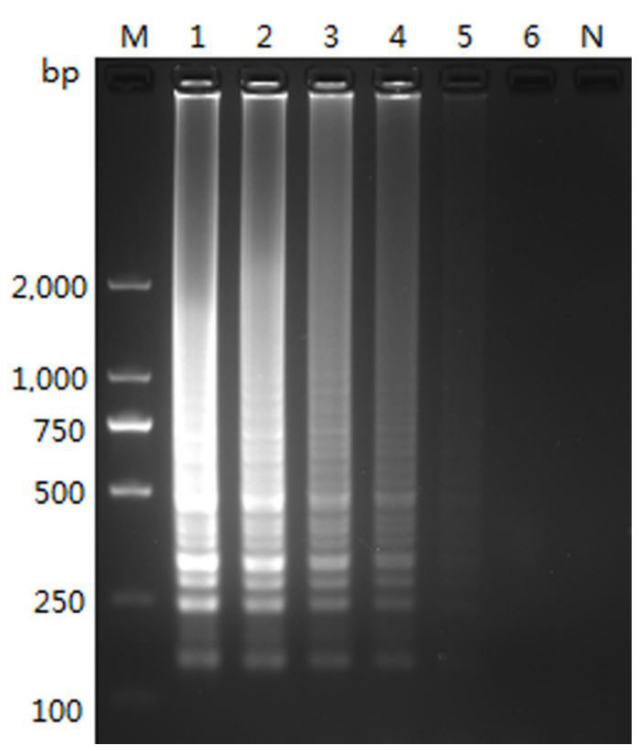

a

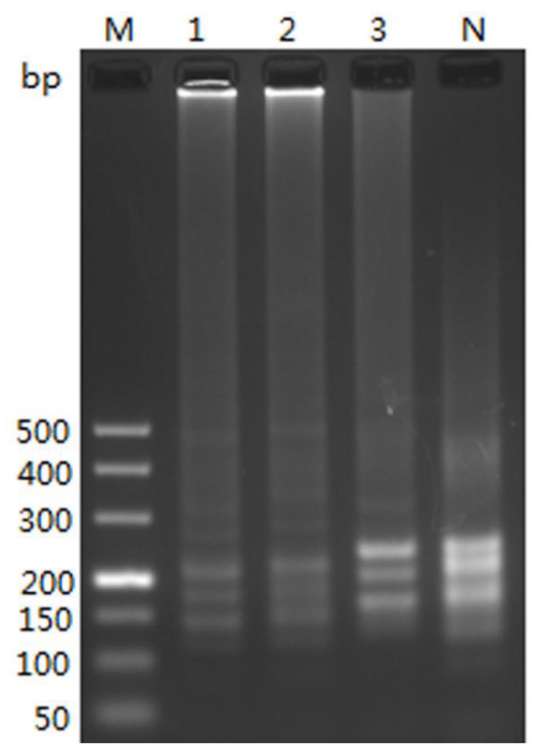

b

Figure 5. Sensitivity of mLAMP assays for artificially contaminated juice. Lanes: M, 2,000-bp DNA marker; (a) 1 6, the numbers of $S$. aureus, Salmonella, and Shigella in artificially contaminated juice sample were 100, 10, 8, 5, 2, and $1 \mathrm{CFU} / \mathrm{mL}$; N, negative control; (b) 1 3, mLAMP products of S. aureus, Salmonella, and Shigella were separately digested by XhoI, KpnI, and BamHI separately; 4, mLAMP products of S. aureus, Salmonella, and Shigella were digested by XhoI, KpnI, and BamHI. Source: by Cong XU.

in the contaminated juice (Figure 5a). Furthermore, mLAMP products were digested by XhoI, KpnI, and BamHI, respectively, to distinguish the products of the three pathogens (Figure $5 \mathrm{~b}$ ).

\section{Discussion}

S. aureus, Salmonella, and Shigella are three important foodborne pathogens that are largely responsible for foodborne illnesses occurring around the world (Wang et al., 2007; World Health Organization, 2015), particularly in developing countries (Von Seidlein et al., 2006). An effective and rapid monitoring mean is thus essential for the control of these three bacterial infections.

LAMP has become a powerful tool to detect foodborne pathogens since it was developed (Maerle et al., 2014; Wang et al., 2007, 2008). Yang et al. (2011) previously reported that the sensitivity of LAMP in detecting $S$. aureus was $1.25 \mathrm{CFU}$ per reaction tube and $10.3 \mathrm{CFU}$ per reaction in the artificial contamination test. Garrido-Maestu et al. (2017) reported systematic loop-mediated isothermal amplification assays were able to detect $<10 \mathrm{cfu} / 25 \mathrm{~g}$ food samples. Shao et al. (2011) established mLAMP to simultaneously detect Salmonella spp. and Shigella spp. in milk, and their detection limits were $100 \mathrm{fg}$ DNA/ tube with genomic DNA and initial inoculation levels of $5 \mathrm{CFU} / 10 \mathrm{~mL}$. Wang et al. (2015) reported a multiple endonuclease restriction real-time LAMP technology for simultaneously differentiating Shigella spp. and Salmonella spp. using 62.5 and 125 fg DNA per tube, respectively.

In the present study, restriction enzyme cleavage sites were designed in each FIP primer, namely, XhoI in nuc FIP, KpnI in fim Y FIP, and BamHI in ipaH FIP. After mLAMP, restriction digestion was performed to distinguish S. aureus, Salmonella, and Shigella or a DNA mixture of any of the three pathogenic bacteria. Both LMAP and restriction digestion were pathogen-specific. The mLAMP LOD for each pathogen were $100 \mathrm{fg}$ DNA/25 $\mu \mathrm{L}$ which is identical to Wang et al. (2015), and 2 CFU/10 mL of initial inoculation in juice. The sensitivity of mLAMP was 10 -fold higher than mPCR, which is the same as that of previous reports (Shao et al., 2011; Wang et al., 2015). Furthermore, in this study, mLAMP can be completed within $20 \mathrm{~h}$ (including culture, DNA extraction, LAMP, enzyme digestion and gel analysis) and is thus superior to traditional methods that are performed within the range of five to seven day (based on the methods protocols). In addition, mLAMP and endonuclease restriction only require a heating block, which is a common laboratory equipment. This study could be applied on preliminary detection of $S$. aureus, Salmonella, and Shigella when SYBR GREEN I is added in the reaction system (data not shown). For as long as any kinds of the above-mentioned bacteria exist in the sample, they could be detected by direct observation, with no need for electrophoresis and enzyme reaction in the preliminary estimation. Restriction enzyme digestion could be further applied in order to determine the species of the pathogenic bacterium.

In conclusion, this study provides a rapid, specific, sensitive, and low-cost assay for the simultaneous detection of $S$. aureus, Salmonella, and Shigella. The detection of these three bacterial pathogens in juice indicates that mLAMP could be potentially used in batches food screening in basic and field laboratories.

\section{Acknowledgements}

The Science and Technology Project of Guangdong Province (No. 2017A020208002) supported this study. 


\section{References}

Amani, J., Ahmadpour, A., Imani Fooladi, A. A., \& Nazarian, S. (2015). Detection of E. coli O157:H7 and Shigella dysenteriae toxins in clinical samples by PCR-ELISA. The Brazilian Journal of Infectious Diseases, 19(3), 278-284. http://dx.doi.org/10.1016/j.bjid.2015.02.008. PMid:25911087.

Chen, Z., Zhang, K., Yin, H., Li, Q., Wang, L., \& Liu, Z. (2015). Detection of Salmonella and several common Salmonella serotypes in food by loop-mediated isothermal amplification method. Food Science and Human Wellness, 4(2), 75-79. http://dx.doi.org/10.1016/j. fshw.2015.05.001.

Food and Agriculture Organization of the United Nations - FAO. World Health Organization - WHO. (2016). Interventions for the control of non-typhoidal Salmonella spp. in beef and pork. Rome. Retrieved from http://www.who.int/foodsafety/publications/mra_30/en/

Garrido-Maestu, A., Fuciños, P., Azinheiro, S., Carvalho, J., \& Prado, M. (2017). Systematic loop-mediated isothermal amplification assays for rapid detection and characterization of Salmonella spp., Enteritidis and Typhimurium in food samples. Food Control, 80, 297-306. http://dx.doi.org/10.1016/j.foodcont.2017.05.011.

Huy, N. T., Hang, L. T. T., Boamah, D., Lan, N. T. P., Van Thanh, P., Watanabe, K., Huong, V. T., Kikuchi, M., Ariyoshi, K., Morita, K., \& Hirayama, K. (2012). Development of a single-tube loop-mediated isothermal amplification assay for detection of four pathogens of bacterial meningitis. FEMS Microbiology Letters, 337(1), 25-30. http://dx.doi.org/10.1111/1574-6968.12002. PMid:22946506.

Imai, M., Ninomiya, A., Minekawa, H., Notomi, T., Ishizaki, T., Tashiro, M., \& Odagiri, T. (2006). Development of H5-RT-LAMP (loopmediated isothermal amplification) system for rapid diagnosis of H5 avian influenza virus infection. Vaccine, 24(44-46), 6679-6682. http://dx.doi.org/10.1016/j.vaccine.2006.05.046. PMid:16797110.

Liu, Z. T., Zeng, J. H., Juan-Juan, L. I., Wan, Q. Q., Wan, R., Si-Yang, Y. U., et al.(2016). Analysis of foodborne disease outbreak incidents in schools in Yunnan Province between 2010 and 2015. Zhongguo Shipin Weisheng Zazhi, 28, 730-734.

Maerle, A. V., Riazantsev, D. I., Dmitrenko, O. A., Petrova, E. I., Komaleva, R. L., Sergeev, I. V., Trofimov, D. Iu., \& Zavriev, S. K. (2014). Detection of Staphylococcus aureus toxins using immunoPCR. Bioorganicheskaia Khimiia, 40(5), 571-577. PMid:25895352.

Notomi, T., Okayama, H., Masubuchi, H., Yonekawa, T., Watanabe, K., Amino, N., \& Hase, T. (2000). Loop-mediated isothermal amplification of DNA. Nucleic Acids Research, 28(12), E63. http:// dx.doi.org/10.1093/nar/28.12.e63. PMid:10871386.

Nouri, A., Ahari, H., \& Shahbazzadeh, D. (2018). Designing a direct ELISA kit for the detection of Staphylococcus aureus enterotoxin A in raw milk samples. International Journal of Biological Macromolecules,
107(Pt B), 1732-1737. http://dx.doi.org/10.1016/j.ijbiomac.2017.10.052. PMid:29030180.

Shao, Y., Zhu, S., Jin, C., \& Chen, F. (2011). Development of multiplex loop-mediated isothermal amplification-RFLP (mLAMP-RFLP) to detect Salmonella spp. and Shigella spp. in milk. International Journal of Food Microbiology, 148(2), 75-79. http://dx.doi.org/10.1016/j. ijfoodmicro.2011.05.004. PMid:21652102.

Sun, X., Ji, Y., Liu, X., Xiang, M., He, G., Xie, L., Suo, J. X., \& Suo, X. (2017). Improvement and evaluation of loop-mediated isothermal amplification for rapid detection of toxoplasma gondii infection in human blood samples. PLoS One, 12(1), e0169125. http://dx.doi. org/10.1371/journal.pone.0169125. PMid:28056092.

Von Seidlein, L., Kim, D. R., Ali, M., Lee, H., Wang, X., Thiem, V. D., Canh, D. G., Chaicumpa, W., Agtini, M. D., Hossain, A., Bhutta, Z. A., Mason, C., Sethabutr, O., Talukder, K., Nair, G. B., Deen, J. L., Kotloff, K., \& Clemens, J. (2006). A multicentre study of Shigella diarrhoea in six Asian countries: disease burden, clinical manifestations, and microbiology. PLoS Medicine, 3(9), 1556-1569. http://dx.doi.org/10.1371/journal.pmed.0030353. PMid:16968124.

Wang, L., Shi, L., Alam, M. J., Geng, Y., \& Li, L. (2008). Specific and rapid detection of foodborne Salmonella by loop-mediated isothermal amplification method. Food Research International, 41(1), 69-74. http://dx.doi.org/10.1016/j.foodres.2007.09.005.

Wang, S., Duan, H., Zhang, W., \& Li, J.-W. (2007). Analysis of bacterial foodborne disease outbreaks in China between 1994 and 2005. FEMS Immunology and Medical Microbiology, 51(1), 8-13. http://dx.doi. org/10.1111/j.1574-695X.2007.00305.x. PMid:17666075.

Wang, Y., Wang, Y., Luo, L., Liu, D., Luo, X., Xu, Y., Hu, S., Niu, L., Xu, J., \& Ye, C. (2015). Rapid and sensitive detection of Shigella spp. and Salmonella spp. by multiple endonuclease restriction realtime loop-mediated isothermal amplification technique. Frontiers in Microbiology, 6, 6. http://dx.doi.org/10.3389/fmicb.2015.01400. PMid:26697000.

World Health Organization - WHO. Food and Agriculture Organization of the United Nations - FAO. (2003). Assuring food safety and quality: guidelines for strengthening national food control systems. Geneva: WHO.

World Health Organization - WHO. (2015). World Health Day 2015: food safety. Geneva: WHO. Retrieved from http://www.who.int/ campaigns/world-health-day/2015/en/

Yang, H., Ma, X., Zhang, X., Wang, Y., \& Zhang, W. (2011). Development and evaluation of a loop-mediated isothermal amplification assay for the rapid detection of Staphylococcus aureus in food. European Food Research and Technology, 232(5), 769-776. http://dx.doi. org/10.1007/s00217-011-1442-8. 